\title{
Desafios para o planejamento no espaço periurbano de Valinhos e Campinas - bairros reforma agrária
}

\author{
Mary Mercia Garberlini Salles* \\ Laura Machado de Mello Bueno ${ }^{* *}$
}

\section{Resumo}

Este artigo apresenta os resultados de uma pesquisa sobre os espaços periurbanos. Analisaram-se as interferências ocorridas no entorno das áreas limítrofes a municípios da Região Metropolitana de Campinas - RMC, no Estado de São Paulo, que se transformaram e que ainda estão em processo de grandes transformações. O referencial teórico apoiou-se em autores de Urbanismo e Turismo, além de outras disciplinas referenciais, das Ciências Sociais. A metropolização brasileira, na qual prepondera a fragilidade do planejamento territorial municipal e regional, tem produzido um espaço periurbano, diferente do subúrbio norteamericano ou dos cinturões verdes de cidades europeias. Verifica-se que o espaço rural é visto como um vazio, ou uma reversa de terras disponíveis para processo de urbanização. Articulam-se interesses locais e externos, até internacionais na reconfiguração destes espaços. Para melhor compreensão deste fenômeno, selecionou-se uma localidade agrícola específica entre Valinhos e Campinas. A abordagem privilegiou o fenômeno periurbano e as possibilidades de implantar o turismo rural como

Turismóloga. Mestre em Urbanismo do Programa de Pós Graduação em Urbanismo do CEATEC da Pontifícia Universidade Católica de Campinas.

Professora com dedicação exclusiva do CEATEC da PUC Campinas, na Faculdade de Arquitetura e Urbanismo e no Programa de Pós Graduação em Urbanismo. Líder do Grupo de Pesquisa Água no meio urbano.

Geosul, Florianópolis, v. 27, n. 54, p 139-164, jul./dez. 2012 
SALLES, M.M.G \& BUENO, L.M.M. Desafios para o planejamento no...

beneficiador do desenvolvimento para a preservação das áreas rurais existentes. Avaliou-se também se há perspectiva promissora de implantação do turismo como ferramenta de alternativa econômica para o produtor rural para promover a conservação do patrimônio ambiental e cultural. A maioria dos produtores apresentou desinteresse em desenvolver qualquer atividade turística. Constatou-se ainda que políticas públicas para transformação das áreas no e do entorno rural são no momento as maiores preocupações dos produtores rurais, exigindo deles novas formas de organização sócio territorial.

Palavras-chave: Gestão urbana; Turismo rural; Espaço periurbano; Produtor rural; Região Metropolitana de Campinas.

Challenges for planning in periurban space of Valinhos and Campinas - agrarian reform neighborhoods

\section{Abstract}

The present research examines the interference occurred in the surroundings of the neighboring areas between two municipalities of the Metropolitan Region of Campinas - RMC, in the state of Sao Paulo, which have been and are still in a process of major modification. The theoretical framework of this study relies on authors specialized on urbanism, tourism and the other disciplines of the social sciences. In the Brazilian metropolization phenomenon the fragility of local and regional planning is noted. A new periurban space is developed, different from the North American suburbia or the green-belts around European cities. The rural areas are seen as an empty space, or a land reserve, available for the urbanization process. Local stackholders and even international interests have been articulated reconfiguring these areas. This paper deals with the contemporary reality of a rural area under the perspective of the periurban phenomenon, which occurs in the RMC. For better understanding of this phenomenon, a 
SALLES, M.M.G \& BUENO, L.M.M. Desafios para o planejamento no...

particular agricultural location in the city of Valinhos and Campinas was selected. The approach favored the periurban phenomenon and the possibilities of implementing rural tourism in a way that it benefits the development and preservation of the available rural areas. It evaluates whether there's a promising prospect of implantation of tourism as an important alternative economic tool for the rural producer and whether it promotes the conservation of cultural and environmental patrimony. The majority of the producers showed lack of interest in the development of any tourist activity. It was found that the public policies for the transformation of the rural areas and its surroundings are, at the time, the greatest concerns of producer, requiring of them new forms of social-territorial organization.

Key words: Urban management; Rural tourism; Periurban space; Local population; Rural producer; Metropolitan Region of Campinas.

\section{Introdução}

O presente trabalho aborda a realidade contemporânea em área rural sob a perspectiva do fenômeno periurbano, que acontece nas metrópoles. As interferências ocorridas no entorno das áreas limítrofes entre os municípios de Campinas e Valinhos, pertencentes à Região Metropolitana de Campinas - RMC - no Estado de São Paulo são a questão central deste estudo.

Para melhor compreensão deste fenômeno, selecionou-se uma localidade específica nos municípios de Valinhos e Campinas. A área em questão, considerada sui genneris, é de um loteamento formado a partir de uma revisão agrária em 1960, sendo popularmente considerada a primeira implantação de reforma agrária no Estado de São Paulo e denominada "Bairro Reforma Agrária". Esta área, servida então pela rodovia Anhanguera, foi posteriormente seccionada pela rodovia dos Bandeirantes, em São Paulo. A retomada da expansão do Aeroporto de Viracopos, 
SALLES, M.M.G \& BUENO, L.M.M. Desafios para o planejamento no...

projeto antigo revigorado pela dinamização do comércio exterior, trouxe novas questões. $\mathrm{O}$ estudo de caso serviu de ferramenta para verificar como o produtor rural, os moradores e a comunidade dos bairros rurais compreendem, se organizam e reagem ao processo de metropolização.

Os problemas das metrópoles brasileiras no contexto da produção capitalista do espaço estão representados neste fragmento territorial quando observamos os diversos conflitos entre a expansão urbana e o enclausuramento da zona rural, ora estudada. No caso das áreas em questão, surgem alguns questionamentos, tais como quais ameaças ao modo de vida tradicional, quais políticas poderiam ser aplicadas para a manutenção do reduto rural com atividades agrícolas atuais e se haveria uma perspectiva promissora para a implantação do turismo rural, como instrumento de conservação das áreas rurais existentes ${ }^{1}$. O processo da pesquisa, metodologicamente calcado na pesquisa-ação e pesquisa participante $^{2}$, levou ao aprofundamento do acompanhamento da discussão da revisão do Plano Diretor Municipal de Campinas e Valinhos e suas consequências para o futuro destas áreas rurais, em um contexto de valorização econômica e ideológica da metropolização globalizante.

1 Este artigo baseia-se na dissertação de Mestrado em Urbanismo "Desafios para o planejamento no espaço periurbano de Valinhos e Campinas - bairros Reforma Agrária", elaborada pela primeira autora, que é turismóloga e até recentemente era produtora rural na região. Daí o interesse em estudar os cinturões verdes às áreas urbanas (espaços periurbanos) e a adequação de integração de atividades de turismo em um contexto rural, oferecidas ao morador das áreas metropolitanas, distantes culturalmente no espaço rural. A segunda autora orientou a pesquisa.

2 Do final de 2008 ao final de 2010 acompanhou-se as reuniões das associações dos produtores, fez-se visitas à suas instalações e houve participação nas reuniões, inclusive as preparatórias, com as prefeituras no processo de discussão dos planos diretores nos dois municípios. 
SALLES, M.M.G \& BUENO, L.M.M. Desafios para o planejamento no...

\section{A região}

A Região Metropolitana de Campinas nasceu do processo de urbanização iniciado nos anos 1950, acelerado na década de 1970, com o aprofundamento da industrialização da capital para o interior, tardia no país, sendo institucionalizada em 2000 através da Lei Complementar Estadual 870.

É constituída por 19 municípios $^{3}$ com área de $3.673 \mathrm{~km}^{2}$ ou $1,5 \%$ do território paulista e 2.633.523 habitantes (2007). Campinas polariza sozinha os municípios de seu entorno e desempenha o papel de centro regional, (CAIADO e SANTOS, 2003 pg.119).

A urbanização da Região Metropolitana de Campinas ocorre principalmente nos eixos viários das rodovias: Anhanguera, denominada SP-330 que faz parte do sistema BR-050, ligando Brasília a Santos com o trecho de maior tráfego entre São Paulo e Campinas, em conjunto com a Rodovia dos Bandeirantes-SP, construída nos anos 1970, que possui traçado paralelo à Via Anhanguera-SP. O Sistema Anhanguera- Bandeirantes liga a RMC à capital paulista e interliga-se a rodovia D.Pedro I, denominada SP-65, viabilizando a ligação com o Vale do Paraíba (São José dos Campos e Taubaté). Por meio do Sistema Dutra-SP e Carvalho Pinto, faz a ligação entre o interior paulista e o litoral norte do estado de São Paulo e o estado do Rio de Janeiro. Essa via cruza também a rodovia Fernão Dias, fazendo o fluxo do interior do país com Belo Horizonte, capital do estado de Minas Gerais. A rodovia Adhemar de Barros (SP-340) liga Campinas ao sul de Minas Gerais e a Rodovia Santos Dumont (SP-75) dá acesso à Rodovia Castello Branco-SP, passando pelo Aeroporto de Viracopos na região sul do município de Campinas.

${ }^{3}$ A Região Metropolitana de Campinas é composta por 19 municípios: Americana, Artur Nogueira, Campinas, Cosmópolis, Engenheiro Coelho, Holambra, Hortolândia, Indaiatuba, Itatiba, Jaguariúna, Monte Mor,Nova Odessa, Paulínia, Pedreira, Santa Bárbara d'Oeste, Santo Antonio de Posse, Sumaré, Valinhos e Vinhedo. 
SALLES, M.M.G \& BUENO, L.M.M. Desafios para o planejamento no...

A expansão urbana ao longo da via Anhanguera se deu principalmente em função do padrão de instalação industrial no processo de interiorização do desenvolvimento que privilegiou grandes eixos rodoviários regionais.

Este movimento de periferização da região foi reforçado pela abertura do Aeroporto de Viracopos, pela implantação do Distrito Industrial de Campinas e pela construção de vários conjuntos habitacionais. No eixo de ocupação ao longo da via Anhanguera quase não existe descontinuidade de ocupação, configurando uma mancha urbana praticamente contínua, que se estende de Vinhedo até Americana, articulando fortemente a economia, o mercado de trabalho e a vida urbana deste conjunto de municípios. (CAIADO e SANTOS, 2003:115).

Essa integração confronta-se com processo de periferização típico das metrópoles de economias pobres, com favelas, loteamentos precários e intensa segregação socioespacial. No sudeste de Campinas e em Hortolândia, Sumaré e Nova Odessa concentra-se a população mais pobre. No norte de Campinas e em Valinhos e Vinhedo concentra-se a população mais rica, em processo de intensa urbanização dispersa pelo meio rural ${ }^{4}$.

Seu território apresenta descontinuidades devido ao processo de urbanização vinculado à expansão da atividade industrial agroindustrial e extensa oferta de loteamentos, associados a grandes centros de compra e entretenimento regionais, posicionados nos eixos viários. "A reestruturação produtiva iniciada no fim dos anos 1980 e acelerada na década de 1990 trouxe a implantação na região campineira de projetos de grande porte de diferentes tipos. Dos 80 empreendimentos em exigência de licenciamento ambiental na região da UGRHI PCJ, 50

${ }^{4}$ Desde os anos 1980 intensificou-se a implantação de loteamentos de alto padrão fechados e condomínios horizontais nestes municípios. Campinas chegou a criar em 1996 um tipo de parcelamento denominado bolsão urbano em área rural, que podia ser aprovado sem conexão com os serviços públicos urbanos. Fonte: Secretaria de Planejamento de Campinas, 2006. 
SALLES, M.M.G \& BUENO, L.M.M. Desafios para o planejamento no...

encontram-se na região metropolitana de Campinas, o que demonstra a atividade econômica deste território ${ }^{5 .}$

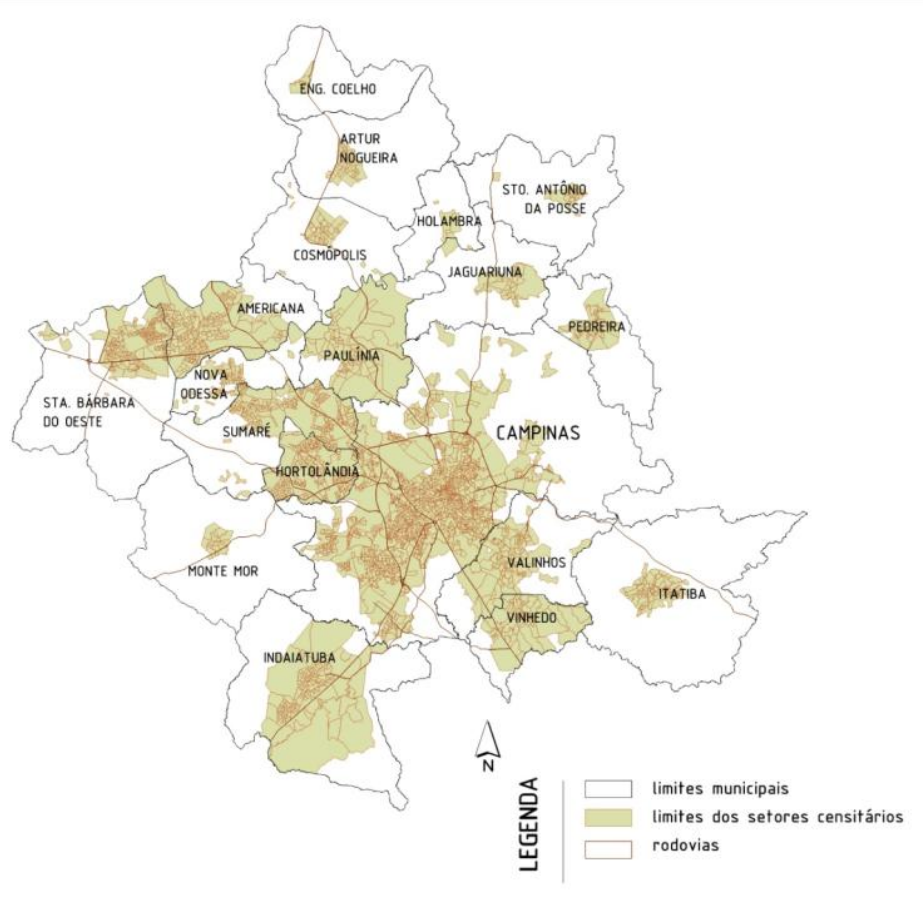

Fonte IBGE. Malha dos Setores Censitários de 2000

FIGURA 1: A região metropolitana de Campinas

O Aeroporto Internacional de Viracopos é o segundo maior do Brasil, representando um terço das mercadorias exportadas e

5 BUENO et al, 2002. Pg. 387. Os dados fazem referência aos empreendimentos com solicitação de EIA RIMA - Estudo de Impacto Ambiental e Relatório dos Impactos ao Meio Ambiente- pela Secretaria de Estado de Meio Ambiente, à época. 
SALLES, M.M.G \& BUENO, L.M.M. Desafios para o planejamento no... importadas pelo país ${ }^{6}$.A perspectiva de sua expansão, mobiliza forças diversas sobre esse território.

Assim, o espaço periurbano da metrópole apresenta intensa transformação. "Observa-se uma nova morfologia do ambiente construído, seja na forma arquitetônica ou na forma urbana, em que a obra implantada - indústrias, shoppings, condomínios e loteamentos de grande porte, parques de lazer, estações de tratamento de esgotos, estradas e aeroportos, entre outros -, desestrutura e reestrutura o território, criando-se novas configurações socioespaciais, especialmente no entorno dos empreendimentos". (BUENO et al. Pg. 388-389)

TABELA 1: Dados selecionados de Campinas e Valinhos

\begin{tabular}{|l|c|c|}
\hline \multicolumn{1}{|c|}{ Município } & Campinas & Valinhos \\
\hline População Total 2007 & 1.039297 & 97814 \\
\hline População urbana 2007 & $98,3 \%$ & $95 \%$ \\
\hline População rural 2007 & $1,7 \%$ & $5 \%$ \\
\hline TGCA 2000-2007 & $1,01 \%$ & $2,4 \%$ \\
\hline Área urbana (hectares) & 39370 & 6590 \\
\hline Área rural (hectares) & 40124 & 8300 \\
\hline $\begin{array}{l}\text { Área total das UPAs (Unidades de } \\
\text { Produção Agrícola) (hectares) (2008) }\end{array}$ & 45172 & 5053 \\
\hline Número de UPAs & 1012 & 420 \\
\hline
\end{tabular}

Fonte: SALLES, 2011

Como pode se ver na Tabela 1, de forma semelhante à maioria dos municípios brasileiros, especialmente os localizados em áreas metropolitanas, Campinas e Valinhos, onde localiza-se a área de estudo, tem poucos habitantes nas áreas rurais $(1,7 \%$ e 5\% respectivamente) . Porém, o número total de UPAs (Unidades de Produção Agrícola) é bastante expressivo, demonstrando o vigor

${ }^{6}$ Fonte: Secretaria de Planejamento de Campinas, 2009. 
SALLES, M.M.G \& BUENO, L.M.M. Desafios para o planejamento no...

da atividade agrícola. Destaque-se que a área rural de Campinas é inferior à área total das UPAs, demonstrando a existência de áreas agrícolas dentro do perímetro urbano. Por outro lado, em Valinhos evidencia-se o contrário, a área total das UPAs, é inferior à área rural, ou seja, na área rural há propriedades não produtivas.

\section{O lugar}

A pesquisa voltou-se para os bairros de Pedra Branca e Reforma Agrária na Macrozona $6^{7}$ de Campinas, que faz limite na região sul leste com o Núcleo Agrário Capivari ou Bairro Reforma Agrária em Valinhos. A estrada asfaltada Luiz de Queirós Guimarães e o rio Capivari, atravessam o Bairro Reforma Agrária em ambos os municípios.

Formada pelos bairros Pedra Branca, Reforma Agrária, Saltinho e Descampado, a região da Pedra Branca (no caminho da Estrada Velha de Indaiatuba), tem como carros-chefes a produção de goiaba e figo para exportação, além de laranja kincan, carambola, acerola, uva, figo, banana, maracujá e pêssego. O Bairro da Pedra Branca teve seu nome inspirado nas pedras de calcário existentes na região.

"Parte do Pedra Branca está localizado dentro do perímetro urbano, o que leva o IBGE a incluí-la em setor censitário urbano. Consequentemente a população aí residente é contabilizada como urbana, mas, de fato, é rural". (Plano Municipal de Desenvolvimento Rural de Campinas, 2010-2013:5).

Uma parcela significativa da produção de goiaba e figo é exportada diretamente pelo agricultor ou através de empresas exportadoras. Oitenta e cinco por cento dos produtores de Campinas que aderiram ao programa de Produção Integrada de Frutas - PIF dofigo - e 50\% dos produtores que aderiram ao PIF da goiaba localizam-se na região da Pedra Branca.

${ }^{7}$ Conforme o Plano Diretor Municipal de 2006, que será apresentado adiante. 
SALLES, M.M.G \& BUENO, L.M.M. Desafios para o planejamento no...

Valinhos é um município com origem rural, com forte presença de migração italianae produção de frutas de mesa em pequenas e médias propriedades. A cultura do figo foi introduzida em Valinhos a partir de 1930. Na década de 1970 a cidade chegou a ter dois milhões de pés de figo. Devido a problemas fitossanitários, nos anos 1970, houve a diversificação de culturas em goiaba e pêssego, além do cultivo de olerícolas. Na década de 1990, Valinhos tornou-se um dos maiores produtores de goiaba do Brasil $^{8}$.

Cerca de $60 \%$ das frutas, como o figo, uva, goiaba, pêssego e caqui comercializados no Circuito das Frutas são cultivadas no Reforma Agrária e na zona rural de Valinhos.

A Associação de Turismo Rural do Circuito das Frutas do Estado de São Paulo foi formada em 2000 com vinte e oito sócios das cidades de Indaiatuba, Itatiba, Itupeva, Jarinu, Jundiaí, Louveira, Valinhos, Vinhedo e Morungabaque têm nas suas economias uma forte presença do setor rural, principalmente da fruticultura.

O Roteiro Rural Circuito das Frutas oferece contato com a história da fruticultura na região, por meio de visitas a pequenas propriedades de agricultura familiar - altamente produtivas que levam para a região a "arte" da produção de frutas. A vida rural, as tradições, os valores e costumes dessas famílias completam o

${ }^{8}$ Segundo o Instituto de Economia Agrícola - IEA, Valinhos é o maior produtor brasileiro de figo in natura para mesa (variedade roxo de Valinhos), a análise ainda aponta que $87 \%$ dos imóveis rurais estão em áreas de pequenas extensões, com características de produção familiar em pequenas propriedades agrícolas, devido ao alto valor agregado da terra. Outro fato que serviu de estímulo para dar continuidade com a cultura da goiaba é que uma família de quatro pessoas consegue "tocar" 500 pés em área um pouco maior que um hectare, compatível com a estrutura fundiária da região. A goiaba vem suplantando a cultura da figueira pelo fato de ser mais resistente para exportação. A preferência européia é pela goiaba branca. 
SALLES, M.M.G \& BUENO, L.M.M. Desafios para o planejamento no...

roteiro. $\mathrm{Na}$ região do Bairro Reforma dois sítios participam do Circuito com visitas ao campo de cultivo.

Esta área entre os municípios de Campinas e Valinhos apresenta uma identidade pelo uso do solo atual e pela origem de sua configuraçãosocioespacial e fundiária, desde os anos 1960, com os mesmos 72 lotes.Na ocasião o Governo Estadual adquiriu parte de uma fazenda, dividiu em lotes, definindo o sistema viário, a escola, o centro comunitário, o clube e uma reserva de mata. Foram construídas casas em alvenaria, pocilgas e um depósito para materiais em cada um dos lotes. (BOMBARDI, 2004).

Devido ao intenso crescimento da área urbanizada, apresenta-se hoje como um território periurbano mascom intensas características rurais. Apesar de o limite municipal dividi-lo, o Reforma Agrária (e os outros bairros rurais do entorno)têm uso do espaço contínuo.

No município de Valinhos, encontra-se um fragmento de mata cortada pelo córrego da Fazenda, afluente do rio Capivari, com 64ha de superfície denominado Parque Estadual ARA. Este parque teve sua origem na mesma iniciativa do governo estadual de implantar na região o projeto piloto de reforma agrária. Daí sua denominação, ARA, as letras iniciais de Assessoria da Reforma Agrária.Em Campinas, localiza-se a captação do rio Capivari, manancial responsável pelo abastecimento de aproximadamente $6,5 \%$ do município.

Os agricultores dos bairros do Reforma Agrária, na sua maioria de origem italiana,agruparam-se desde os anos 1960 em associações com outros agricultores de origem japonesa, que na maioria permanecem no Macuco, em Valinhos e no Pedra Branca, em Campinas, como prerrogativa para posse da terra era obrigatório serem agricultores. O Associativismo permitiu que se organizassem de tal forma que homogenizaram a espécie mais adequada ao tipo de solo e ao clima, ou seja, o figo roxo.Também tinham raízes rurais e foram atualizando-se em suas formas de produção, beneficiando-se da localização. São agricultores bem sucedidos. Desde o acesso à terra em 1962, as famílias se 
SALLES, M.M.G \& BUENO, L.M.M. Desafios para o planejamento no...

mantiveram organizadas e vem trabalhando arduamente, buscando e conseguindo acesso a assistência técnica, tecnologia agropecuária, até por sua localização em região de grande acúmulo em pesquisa voltada à agricultura ${ }^{9}$.

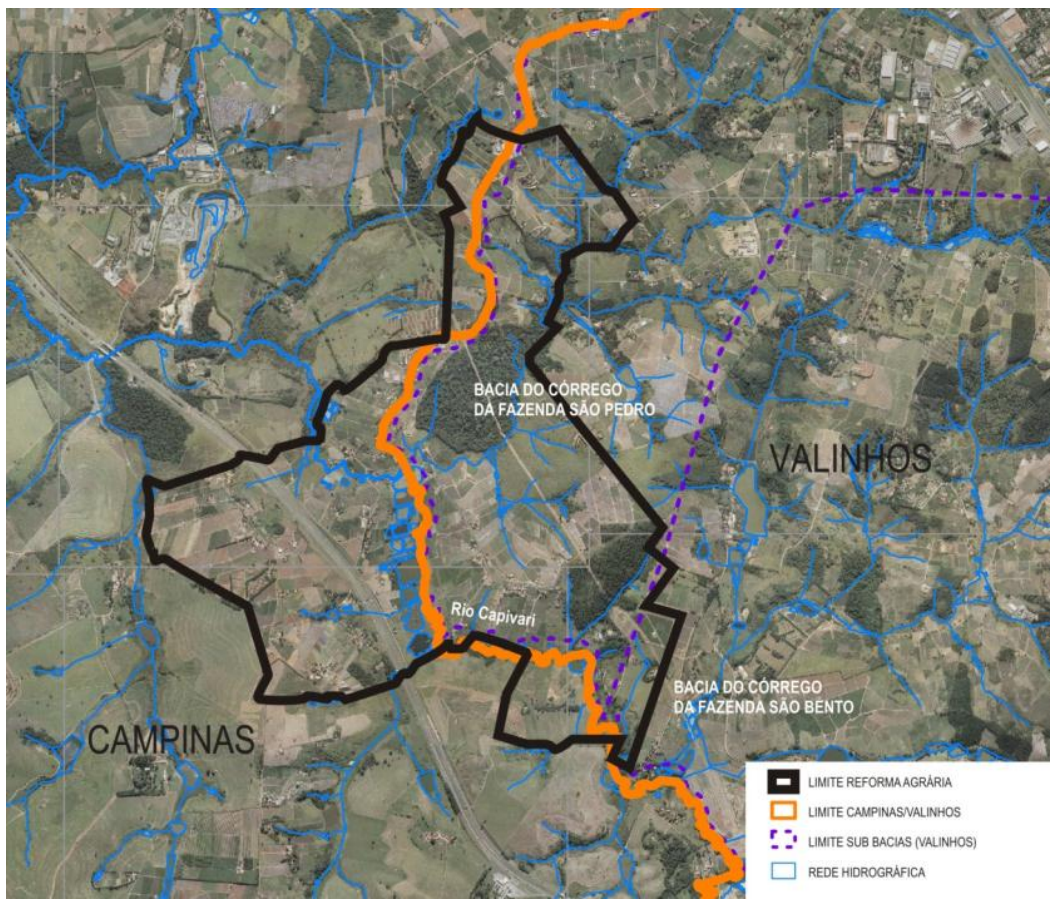

FIGURA 2: Fotografia aérea coma a delimitação do Reforma Agrária

Por outro lado, esses agricultores não criaram relações de dependência de caráter tradicional, populista, com o poder municipal. Por terem obtido sucesso econômico com a atividade principal, puderam dar sustento e melhorar a qualidade de vida dos

9 Na região estão presentes o Instituto Agronômico de Campinas, a EMBRAPA e a UNICAMP, por exemplo) 
SALLES, M.M.G \& BUENO, L.M.M. Desafios para o planejamento no...

familiares, sem criar laços de dependência com as estruturas públicas locais e mantendo-se na área rural. Seus filhos e netos, quando decidiram mudar-se para a cidade, o fizeram por opção, e não por constrangimentos econômicos típicos do fenômeno brasileiro de migração campo-cidade.

O desinteresse ou mesmo aversão ao dinamismo do entorno urbanizado e as atividades de turismo rural percebido na pesquisa por parte da maioria dos agricultores do bairro Reforma Agrária nos trechos de Campinas e Valinhos, decorre de fatores de natureza sociais e culturais diversas. O mercado das frutas de mesa está próximo, devido à relativa proximidade da Grande São Paulo e os associados souberam inserir-se no circuito de exportação. Tiveram capacidade empresarial de fazê-lo e souberam desenvolver sua produção atendendo os requisitos desse mercado, bem mais exigente e lucrativo do que o mercado interno. Assim, orgulham-se de que seu bem estar vem da agricultura e não necessitam de uma "renda extra", que seria um objetivo colocado pelos idealizadores do Circuito das Frutas.

Os agricultores do Bairro Reforma Agrária têm uma prática "profissional", "moderna" em sua atividade principal - a produção agrícola. Em poucas propriedades percebe-se espaço para hortas, pomares, criação de galinhas ou outros animais para consumo familiar. Morando perto da área urbana e particularmente, de cidades ricas e bem estruturadas como Campinas e Valinhos, desenvolveram padrões de consumo eminentemente urbanos, diríamos até metropolitanos. $\mathrm{O}$ acesso dos filhos à educação pela localização metropolitana também rendeu frutos que trazem características específicas. Muitos dos filhos e netos, ao constituir família, tem empregos e moram no meio urbano. Há na família pessoas que fizeram curso superior voltado aos negócios da família e outros se afastaram, integrando-se mais ao espírito urbano metropolitano.

Para os moradores a presença de turistas nos finais de semana traria a eles certo desconforto, pois nos fins de semana preferem ficar com a família, sem a presença de estranhos. E é no 
SALLES, M.M.G \& BUENO, L.M.M. Desafios para o planejamento no...

fim de semana que filhos e netos que moram na cidade, osvêm visitar. A necessidade de tranquilidade e privacidade sobrepõe-se à ânsia do homem urbano, metropolitano, das múltiplas atividades, da agitação, do contato humano superficial e diversificado.

Essa presença de valores socioculturais de ruralidade nos moradores do Reforma Agrária causa estranheza, pelo fato de não estar associada à imagem que a cultura urbana faz do campo brasileiro, do caipira, pobre, inculto, atrasado.

Os agricultores moradores não se identificam com a questão metropolitana, colocada pelos poderes municipais na discussão sobre o uso de seu território nos planos diretores. Se utilizam da metrópole como o homem rural se utiliza da cidade, apesar de próxima fisicamente, distante socioculturalmente.

Da mesma forma, o poder municipal, percebe a área rural (e seus moradores e atividades) como resíduo, reserva. $\mathrm{O}$ futuro do município, para progresso e desenvolvimento, é urbanizar totalmente seu território. São áreas que um dia irão se tornar urbanas, oferecendo-se à especulação imobiliária e aos novos desejos e necessidades do crescimento econômico.

Especialmente neste contexto de metropolização que acomete Campinas e seu entorno durante os anos 1980, a política territorial não tem instrumentos nem se volta a manter um cinturão verde produtivo. Ao contrário, no município de Valinhos há um estímulo à transformação de sítios e fazendas em loteamentos de chácaras e loteamentos que se fecham, denominando-se condomínios horizontais, até a divisa com o bairro Reforma Agrária. Em Campinas, essa região é vista pelo planejador dos anos 1980 como um território vazio, através do acesso pela Rodovia Santos Dumont ao Distrito Industrial e ao Aeroporto de Viracopos, sendo então possível "conciliar" o uso residencial popular, pequenas e médias instalações com galpões.

A proximidade com os núcleos urbanos, e a facilidade de acessibilidade são as duas principais razões que explicam a formação e a expansão dos espaços periurbanos em Valinhos e Campinas. 
SALLES, M.M.G \& BUENO, L.M.M. Desafios para o planejamento no...

Como pode ser observado tanto em Campinas quanto em Valinhos, considerando a localização desta área junto a importantes rodovias que dão acesso direto à capital do Estado e ao interior do mesmo. A proximidade com os centros urbanos mobiliza os moradores rurais para o consumo nos supermercados locais e regionais, já que nesse processo de metropolização, a mulher também passa a estudar e trabalhar fora de casa, o que pode levar ao desinteresse na produção de subsistência.

\section{O fenômeno do espaço periurbano}

Inúmeros conceitos são usados na discussão do desenvolvimento de áreas que se relacionam e interagem entre o rural e o urbano, dos que mais aproximam do cenário brasileiro e se destaca como fenômeno é o periurbano, e seria para FURTADO a “(...) visão de que estas áreas se configuram a partir de intervenções estatais, ações práticas oriundas da ausência ou fragilidade das políticas públicas de regulação ou provisão de serviços, e estratégias cotidianas dos habitantes em termos de sobrevivência econômica, apropriação e construção de espaços para moradia e outros usos". (FURTADO, 2007).

O espaço periurbano na Região Metropolitana de Campinas - RMC vem sofrendo modificações no uso do solo, assim como muitas cidades brasileiras, principalmente as que se encontram no entorno das metrópoles, em função da expansão urbana e da ocupação do espaço rural por atividades não agrícolas como o turismo e o lazer e em concordância com FURTADO (2007) quanto à fragilidade das políticas públicas na apropriação e construção de espaços para moradia e outros usos podem ser identificados tanto em Campinas quanto em Valinhos.

DÉZERT, METTON e STEINBERG (1991) (apud ESTANQUEIRO, 2007 pg. 23) destacam um conjunto de fatores que fundamentam a diversidade tipológica de ocupação periurbana: "estrutura fundiária rural, tipos de construção do edificado (das moradias), modalidades de financiamento da construção, níveis de 
SALLES, M.M.G \& BUENO, L.M.M. Desafios para o planejamento no...

organização e de estruturação imobiliária e, em particular, os tipos de urbanização pré-existentes".

ESTANQUEIRO (2007) destaca que a estrutura fundiária, a proximidade do centro urbano e o baixo custo do uso desse espaço, quando comparado ao espaço urbanizado, geram renda e emprego para populações urbana e rural, em razão de sua área multifuncional que também pode ser identificada no bairro estudado.

Há evidências de uma tradição entre as famílias rurais de diversificar o uso da força de trabalho, combinando entre seus membros o exercício de atividades agrícolas e não-agrícolas como estratégias de complementação de suas rendas médias. (GRAZIANO DA SILVA, 2000). A combinação dessas atividades numa mesma unidade de produção familiar é definida como um fenômeno, o da pluriatividade. Porém, no caso da RMC, as atividades não agrícolascaracterizam-se pela coexistência de funções, em atividades laborais ou profissionais tanto dentro da unidade produtora quanto na zona urbana, o que poderíamos definir como espaços multifuncionais devido principalmente pela permanente transformação econômica, social e física.

Em Campinas, a área de transição rural - urbana, apresenta a proliferação de loteamentos destinados à moradia popular, em grande parte, criada por políticas públicas de habitação do município. Em Valinhos, houve uma ampliação do uso habitacional através da intensificação das chácaras de recreio e loteamentos fechados.

Outras atividades, além da agrícola, foram identificadas especialmente do lado campineiro, como a ação das mineradoras, os pátios de armazenamento de veículos de carga, as máquinas de beneficiamento de arroz, a usina de asfalto, as sucatas, as indústrias químicas e metalúrgicas. São atividades que, juntamente com os núcleos urbanos, provocam impactosmais significativos, que os associados à atividade agrícola. 
SALLES, M.M.G \& BUENO, L.M.M. Desafios para o planejamento no...

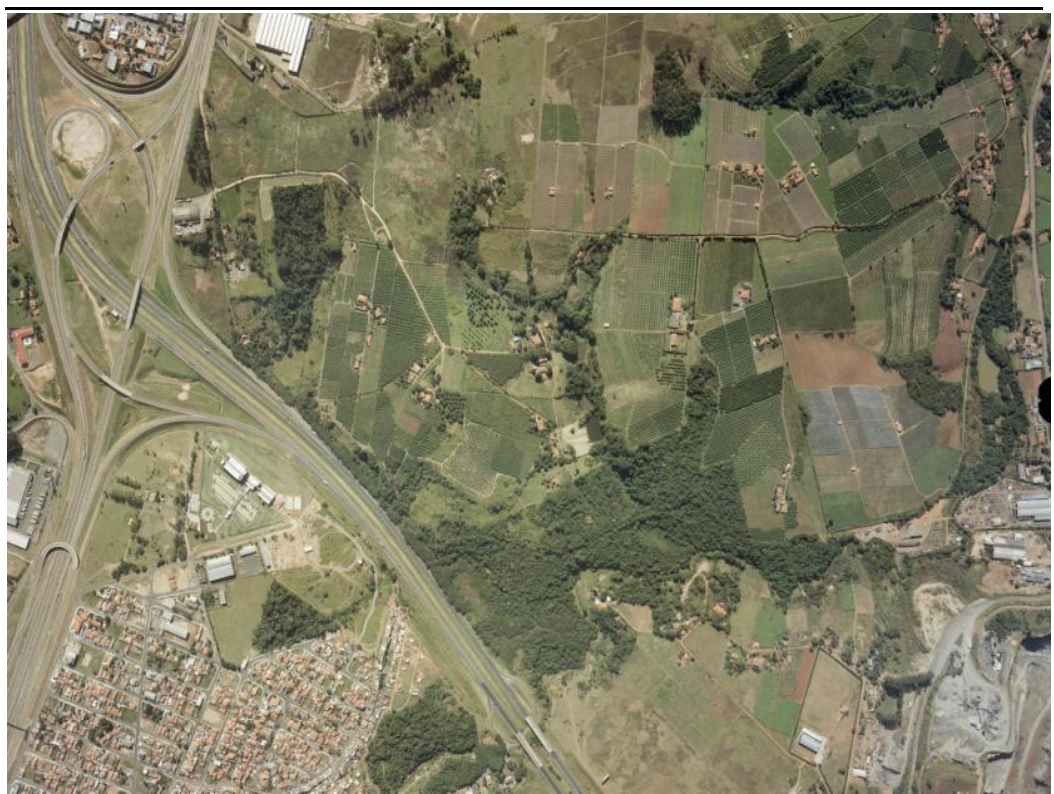

FIGURA 3: Trecho do de área periurbana próxima ao Reforma Agrária em Campinas em 2006

Vê-se à direita abaixo, atividade mineradora e galpões industriais e à esquerda cruzamento entre rodovias dos Bandeirantes e Santos Dumont, com loteamentos populares e indústrias.

Pequenos agrupamentos urbanos podem ser encontrados, sendo o maior deles o Parque Centenário, caracterizado como ocupação conforme lei orgânica do município de Campinas ${ }^{10}$. A infraestrutura dessa ocupação é bastante precária, o que leva seus

${ }^{10}$ Os moradores destas ocupações não têm participado de nenhuma plenária organizada pela Prefeitura, segundo dados da SEPLAMA, Campinas. 
SALLES, M.M.G \& BUENO, L.M.M. Desafios para o planejamento no...

habitantes a utilizarem os equipamentos sociais de bairros distantes, muitos deles em Valinhos.

Ao se introduzirem usos não-agrícolas nestas regiões rurais, dificulta-se a comunicação entre as propriedades, bem como a circulação de máquinas e a rápida comercialização dos produtos. Passam a ser frequentes as ocorrências de violações da propriedade e a destruição de cultivos, principalmente em propriedades que se localizam próximos às vias de comunicação, representando grandes perdas para os agricultores.

Segundo os agricultores, estas ocupações são motivo de muitas preocupações há muitos anos, em razão dos impactos na área rural decorrentes da poluição hídrica por falta de coleta e tratamento de esgotos. Os recursos hídricos tornam-se inúteis para irrigação, higienização da produção e abastecimento. $\mathrm{O}$ roubo de frutas, uma das grandes preocupações dos moradores agricultores, leva ao abandono do cultivo.

O aeroporto de Viracopos também é objeto de atenção aos conflitos que estão em processo em razão da ampliação que se projeta para um futuro próximo, sendo certamente seu principal agente.

No caso específico do Núcleo Agrário Capivari em Valinhos, a relação entre os espaços periurbanos compreende áreas de complexa transição rural-urbana decorrente da expansão de loteamentos fechados destinados às classes média e alta; dos conflitos e tensões em relação ao uso do solo por novas atividades, como é o caso dos estabelecimentos comerciais e industriais, lazer e as culturas agrícolas; da demanda por novos serviços urbanos, como transporte público e saneamento básico e a ampliação dos problemas ambientais, como resíduos sólidos e contaminação das águas por esgotos domésticos e por agrotóxicos.

Os processos especulativos e a demanda por moradia popular, no caso de Campinas, e a busca por tranquilidade, associada ao encontro com a natureza, no caso de Valinhos, são fatores fundamentais, confirmando a "conformação e/ou justaposição de três espaços interdependentes: o rural, o natural e o 
SALLES, M.M.G \& BUENO, L.M.M. Desafios para o planejamento no...

urbano", como sugerem os estudos de VALE (2006) e ENTRENA DURÁN (2003).

Nesses espaços, a distinção entre campo e cidade torna-se complexa em razão de as periferias citadinas aumentarem sua extensão e, sobretudo, tornarem os limites entre as áreas urbanas e rurais cada vez mais indefinidos.

\section{Os planos diretores municipais e o espaço periurbano metropolitano}

Desde 2001, com a aprovação da Lei Federal 10257 Estatuto das Cidades, os municípios com mais de 20.000 habitantes devem elaborar ou revisar seus PDs, incorporando novos instrumentos de política urbana. Uma das diretrizes do Estatuto (art. $2^{\circ}$.) é que os PDs devem tratar da totalidade do seu território, ou seja, as áreas urbanas e rurais.

O PD de Valinhos foi elaborado em 2004, dividindo o município em seis macrozonas (MZ), quando se manteve o bairro Núcleo Agrário Capivari ou Reforma Agrária como rural, na MZ rural agrícola.

O município de Campinas revisou seu PD em 2006, dividindo seu território em novemacrozonas. O trecho campineiro do Bairro Reforma Agrária está localizado na MZ 6 - área de vocação agrícola.

O novo Plano Diretor de Campinas, aprovado em 2006, determinou a elaboração e a implantação de Planos Locais de Gestão (PLGs) para as Macrozonas (regiões pré-estabelecidas com base na instituição de critérios específicos de parcelamento, ocupação e uso do solo).

Dentre as reuniões, a de maior relevância foi a de 29/09/2009, em que os produtores rurais se reuniram nas instalações da Associação Nipo Brasileiro Pedra Branca em Campinas, realizou-se a $33^{\mathrm{a}}$ reunião extraordinária do CONCIDADE quando o secretário em exercício de Planejamento e Desenvolvimento Urbano de Campinas apresentou as 
SALLES, M.M.G \& BUENO, L.M.M. Desafios para o planejamento no...

características da Macrozona, em que expõe o significado do Plano Local e a sua finalidade, tais como: a adequação das medidas de parcelamento; uso e ocupação do solo às condições ambientais, urbanística e sócia econômica; pormenorizar as políticas setoriais e definir as diretrizes viárias e de preservação e recuperação ambiental.

Em suas falas, os moradores cobram da Prefeitura a implementação das reivindicações feitas no passado, principalmente sobre a proposta ao Governo Estadual de inclusão de Campinas no Circuito das frutas.

Foram também feitas muitas perguntas e questionamentos sobre os grandes projetos de ampliação no anel viário de Campinas, que seccionaria ainda mais o Reforma Agrária, sobre o TAV (Trem de Alta Velocidade), sobre a liberação do zoneamento para habitação. A resposta da instituição foi burocrática, de que as propostas eram relativas a outras instâncias não incluídas no PLG, e que seriam encaminhadas.

Existe um descompasso entre a comunidade dessa região e prefeitura. Pode-se apontar como divergência crucial entre moradores e poder público, o fato de que o Estatuto das Cidades, segundo o secretário de Planejamento de Campinas, não estabelece melhorias de infraestrutura antes da regulação das diretrizes.

O esvaziamento das reuniões que se seguiram à reunião com o secretário da SEPLAMA pode ser explicado pela evidente insatisfação dos moradores quanto a problemas reivindicados anteriormente, como o ingresso dos produtores no Circuito das Frutas $^{11}$ foi mencionado inúmeras vezes.

Em Valinhos, o chamado Plano Diretor II de 1996 foi revisado em 2004 e concluído parcialmente em 2006, denominadose o plano o PD III.A Secretaria de Meio Ambiente e Urbanismo foi responsável pela coordenação do Plano que definiria o

${ }^{11}$ Os municípios participantes têm resistência à entrada de Campinas, que consideram um município forte, e não caracterizado como interior. 
SALLES, M.M.G \& BUENO, L.M.M. Desafios para o planejamento no...

desenvolvimento da cidade para os próximos dez anos, juntamente com outras secretarias.

Os temas propostos foram discutidos através dos Conselhos Municipais, vereadores, organizações não governamentais (ONGs) e outras entidades e o anteprojeto analisado pelos Conselhos de Meio Ambiente e Planejamento.

Audiências públicas e reuniões do conselho contaram com participação expressiva da população e por esse motivo, a nova proposta de zoneamento levou um maior tempo para ser aprovada.

Em 2008 o município foi surpreendido com uma nova proposta do Executivo municipal de criação de uma grande área para logística no município, alcançando toda a área rural.

Diante desta mensagem, as associações, ONGs, produtores rurais e vereadores se mobilizam e durante audiência pública questionam e levam ao executivo a proposta de uma análise ambiental. É criada uma comissão de sistematização com membros da secretaria de planejamento e vereadores, que conclui que as áreas são passíveis de transformação em 18/04/2009. Há uma mobilização da Ordem dos Advogados do Brasil - OAB local.

$\mathrm{Na}$ elaboração dos PDs, a participação da sociedade foi bem recebida e representada junto aos poderes instituídos, porém em 13 de janeiro de 2010, o prefeito em exercício, envia projeto de lei em que propõe a criação de uma área destinada às atividades de logística.

Trata-se de uma área de 6,2 milhões de metros quadrados na região do Bairro Reforma Agrária, declarado pelo proprietário como terra improdutiva ${ }^{12}$, próxima à Rodovia dos Bandeirantes na, divisa com o município de Vinhedo e com o acesso à Rodovia

${ }^{12}$ Segundo o Boletim de Notícias da Prefeitura de Valinhos, “A área, de propriedade particular, é totalmente improdutiva e um dos seus proprietários, o ex-governador Orestes Quércia, relatou ao prefeito Marcos que pretende implantar um condomínio de galpões industriais que poderá gerar cinco mil empregos. 
SALLES, M.M.G \& BUENO, L.M.M. Desafios para o planejamento no...

Miguel Melhado Campos que faz a ligação de Vinhedo com o Aeroporto de Viracopos.

Em Campinas, a discussão sobre o Plano Local da Macrozona -MZ 6, o Bairro Reforma Agrária é visto de forma idealizada pelos técnicos, tendo o planejador como arma contra a expansão territorial das áreas de indústria e logística, o fortalecimento do cinturão verde de Campinas através do turismo rural. Mas ao mesmo tempo, liberam-se diversas glebas para implantação de conjuntos habitacionais populares do Programa Minha Casa Minha Vida, que aumenta a densidade, os resíduos, os poluentes e os conflitos entre a prática agrícola e o comportamento citadino.

Para o produtor rural, a expansão de Viracopos, por um lado apresenta-se positiva, pois ampliaria suas condições de escoamento da produção para mercados qualificados. Entretanto, estando tão perto fisicamente do equipamento, os sítios acabam por sofrer os impactos da obra. Assim, os terrenos são cobiçados para outras atividades, de apoio justamente ao escoamento de produtos, em escala macro regional e global. Assim, no processo de mais de um ano de acompanhamento da discussão sobre esse território, percebeu-se que os proprietários rurais sentem-se vencidos pela lógica da metropolização capitalista. Sentem-se consternados por estarem perdendo aquelas ótimas condições para a agricultura e pelo fato de que os municípios não reconheceremseu papel social de cinturão verde e colocam então advogados para defender seus direitos. Ou seja, para garantir que ficarão com uma parcela da enorme valorização imobiliária que as mudanças da legislação parecem produzir.

\section{Considerações finais}

A interpretação dos resultados da pesquisa considera que os espaços periurbanos e os espaços rurais devem ser tratados como elementos de um sistema único, em concordância com ESPANÃ (1991) de que o espaço periurbano deve ser analisado por meio de 
SALLES, M.M.G \& BUENO, L.M.M. Desafios para o planejamento no...

suas interações tanto com a cidade quanto com o espaço rural, considerando o conjunto de processos econômicos e socioculturais que exercem pressões sobre o meio rural que, no caso, apresenta-se passivo diante delas.

As áreas periurbanas de Valinhos e Campinas contam uma história não acabada para o processo de urbanização frente às interferências dos poderes públicos nos dois municípios, cujos Planos Diretores revelam-se totalmente ineficazes para garantir a manutenção de um cinturão verde que minimizasse os impactos negativos da conurbação da urbanização, como o encarecimento do acesso à produção agrícola e a ampliação do fenômeno da ilha de calor, diante das pressões da metropolização do espaço no contexto do comércio global.

O planejamento municipal em Campinas e Valinhos reconhecia a atividade agrícola em seus primeiros planos. Mas atualmente enfatizam a problemática urbana, focando o espaço rural como o que ainda não é urbano, não como um espaço com características próprias.

Recentemente propõem - se a extinção dessas áreas e a adoção do conceito de que tudo é cidade, com a ausência da atividade rural no modelo espacial.

A administração municipal de Campinas tem se apoiado no Plano de Gestão Local, promovendo reuniões com moradores tanto rurais quanto urbanos para cumprimento das regras do Estatuto da Cidade, principalmente quanto à participação da sociedade civil. $\mathrm{O}$ esvaziamento das reuniões, como se pôde observar pela pesquisadora com o contributo da metodologia participante, é sintoma de que decisões sobre os grandes empreendimentos, tais como a ampliação do aeroporto de Viracopos, o traçado do trem de alta velocidade, o Anel viário e a localização dos projetos habitacionais Minha Casa, Minha Vida, não estão no âmbito do plano local e, portanto, não são matéria de deliberação dos moradores.

No caso de Valinhos, a compra de terras rurais para fins especulativos confirma que as diretrizes do Estatuto da Cidade 
SALLES, M.M.G \& BUENO, L.M.M. Desafios para o planejamento no...

servem de pretexto para realizar modificações em prejuízo do interesse público, (BUENO, 2007). A sociedade civil de Valinhos tem se pronunciado para impedir os avanços da urbanização sobre as zonas agrícolas através de representações junto ao poder judiciário e também por meio da presença significativa de moradores nas audiências públicas promovidas pela Câmara Municipal, principalmente de produtores agrícolas, pois sentem que suas áreas de cultivo podem se tornar improdutivas.

Em contrapartida, empreendedores imobiliários/ proprietários fundiários/grande capital e poder público também se articulam visando outros interesses no uso do solo, como se pôde constatar através do acompanhamento, nesses dois anos de estudo, do Núcleo Agrário Capivari ou Reforma Agrária. A pressão exercida sobre os pequenos e médios proprietários de terra pelos especuladores recebe apoio do poder executivo. Os anos de luta na construção e manutenção do território rural estão sucumbindo à hegemonia do capital na produção da cidade e do lugar e faz emergir a desigualdade e a expropriação do espaço comunitário.

Apesar das iniciativas dos governos federais e estaduais com programas como o Programa Nacional de Fortalecimento da Agricultura Familiar-PRONAF, Bolsa Família, Microbacias, no caso do governo do Estado de São Paulo, e outros, mais esforços deveriam ser feitos associando os conceitos de multifuncionalidade e pluriatividade, ou seja, relacionando-se aspectos econômicos, sociais e ambientais com uma reorientação estratégica para o fortalecimentoda agricultura familiar, com programas que permitam novas atividades, novas funções.

Os programas devem estimular demandas, criar mercados envolvendo a sociedade urbana e rural na remuneração de suas funções, o turismo por exemplo. São necessárias outras políticas territoriais que respeitem as especificidades de cada sistema agrário e estimulem a aplicabilidade do conceito de multifuncionalidade das unidades espaciais.

A multifuncionalidade pode ser um instrumento de implementação da função social da propriedade rural, voltada para 
SALLES, M.M.G \& BUENO, L.M.M. Desafios para o planejamento no...

a desapropriação dos imóveis improdutivos. Considerando a realidade apresentada no estudo de caso, conclui-se que a distribuição das terras ainda é um elemento importante na questão agrária para a geração de novas funções agrícolas como elemento fortalecedor da agricultura familiar.

\section{Referências bibliográficas}

BOMBARDI, L. M.“O Bairro Reforma Agrária e o Processo de Territorialização Camponesa". São Paulo, Annablume, 2004, 395p.

BUENO, Laura. M. DE M. "Inovações para a caracterização dos direitos à cidade: limites e possibilidades da lei e da gestão”. Org. BUENO. L.M.M. e Cymbalista, R. São Paulo: Annablume, 2007.

BUENO. Laura. M.M., MACHADO Maria H. F e SILVA FILHO. Nelson M. Limites e Possibilidades da Gestão Compartilhada de Interesses Comuns. IN FONSECA. R. B. DAVANZO A. M. Q. NEGREIROS R. M. C. Livro Verde: desafios para a gestão da Região Metropolitana de Campinas. UNICAMP. IE. 2002.

CAIADO, Aurílio. S. C. e SANTOS, S. M. "Fim da dicotomia rural-urbano? Um olhar sobre os processos sócios espaciais". In São Paulo em Perspectiva, 17 (3-4): 115-124, 2003.

ENTRENA D. (2003: 57), apud ESTANQUEIRO, R.L. da S.: "Metodologia Para Identificação das Margens Urbanas Metropolitanas por Abordagem Multi-Estrategica - Uma aplicação a área metropolitana de Lisboa": Tese de Mestrado, Universidade Nova de Lisboa, Janeiro de 2007. 
SALLES, M.M.G \& BUENO, L.M.M. Desafios para o planejamento no...

ESPAÑA, E.D. "La agricultura em espacios periurbanos em el município de Alboraya,Valencia" Universidade de Valencia, 1991.

FURTADO, Maria. de F. R. de G. " A gestão urbana e regional e as áreas de interface periurbana". XII Encontro da Associação Nacional de Pós-Graduação e Pesquisa em Planejamento Urbano e Regional - ANPUR 2007/ 21 a 25 de maio de 2007. Belém, Pará - Brasil. FURTADO, 2007).

GASPARINI, D. "O município e o parcelamento do solo urbano”, p.182.Saraiva, 1988.

GRAZIANO DA SILVA, J. "O novo rural brasileiro.Campinas”: IE - UNICAMP. 1999/2000. Disponível em: www.eco.unicamp.br.

PREFEITURA DO MUNICIPIO DE CAMPINAS - PMC, SECRETARIA DE PLANEJAMENTO - SEPLAMA, disponível em www.campinas.gov.br

PREFEITURA DO MUNICIPIO DE VALINHOS - PMV disponível em www.valinhos.gov.br.

SALLES, Mary M.G. "Desafios para o Planejamento no Espaço Periurbano de Valinhos e Campinas - Bairros Reforma Agrária”. Dissertação de Mestrado em Urbanismo da Pontifícia Universidade Católica de Campinas, 2011.

Recebido em novembro de 2011 Aceito em março de 2012 